\title{
Rapid detection of ERG I I gene mutations in clinical Candida albicans isolates with reduced susceptibility to fluconazole by rolling circle amplification and DNA sequencing
}

\author{
Huiping Wang ${ }^{\dagger}$, Fanrong Kong ${ }^{\dagger 2}$, Tania C Sorrell ${ }^{2}$, Bin Wang 3 , \\ Paul McNicholas ${ }^{4}$, Namfon Pantarat ${ }^{2}$, David Ellis ${ }^{5}$, Meng Xiao ${ }^{6}$, \\ Fred Widmer ${ }^{2}$ and Sharon CA Chen*2
}

\begin{abstract}
Address: ${ }^{1}$ Department of Dermatology, Tianjin Medical University General Hospital, Tianjin Medical University, Tianjin, PR China, ${ }^{2}$ Centre for Infectious Diseases and Microbiology, The University of Sydney, Westmead Hospital, Sydney, Australia, ${ }^{3}$ Retroviral Genetics Laboratory, Centre for Virus Research, Westmead Millennium Institute and the University of Sydney, Sydney, Australia, ${ }^{4}$ Schering-Plough Research Institute, Kenilworth, New Jersey, USA, ${ }^{5}$ Mycology Unit, Women's and Children's Hospital, Adelaide, Australia and ${ }^{6}$ Life Science College, Peking University, Beijing, PR China

Email: Huiping Wang - huiping1208@163.com; Fanrong Kong - fanrong.kong@swahs.health.nsw.gov.au;

Tania C Sorrell - tsorrell@usyd.edu.au; Bin Wang - bin_wang@wmi.usyd.edu.au; Paul McNicholas - paul.mcnicholas@spcorp.com;

Namfon Pantarat - namfon.pantarat@swahs.health.nsw.gov.au; David Ellis - deelis@adelaide.edu.au;

Meng Xiao - cjtcxiaomeng@yahoo.com.cn; Fred Widmer - fred.widmer@swahs.health.nsw.gov.au;

Sharon CA Chen* - sharon.chen@swahs.health.nsw.gov.au

* Corresponding author †Equal contributors
\end{abstract}

Published: 14 August 2009

BMC Microbiology 2009, 9:167 doi:10.1 186/147/-2180-9-167

This article is available from: http://www.biomedcentral.com//47/-2/80/9//67

(c) 2009 Wang et al; licensee BioMed Central Ltd.

This is an Open Access article distributed under the terms of the Creative Commons Attribution License (http://creativecommons.org/licenses/by/2.0), which permits unrestricted use, distribution, and reproduction in any medium, provided the original work is properly cited.

\begin{abstract}
Background: Amino acid substitutions in the target enzyme Ergl I of azole antifungals contribute to clinically-relevant azole resistance in Candida albicans. A simple molecular method for rapid detection of ERGII gene mutations would be an advantage as a screening tool to identify potentially-resistant strains and to track their movement. To complement DNA sequencing, we developed a padlock probe and rolling circle amplification (RCA)-based method to detect a series of mutations in the $C$. albicans ERGII gene using "reference" azole-resistant isolates with known mutations. The method was then used to estimate the frequency of ERGI I mutations and their type in 25 Australian clinical $C$. albicans isolates with reduced susceptibility to fluconazole and in 23 fluconazole-susceptible isolates. RCA results were compared DNA sequencing.
\end{abstract}

Results: The RCA assay correctly identified all ERGII mutations in eight "reference" C. albicans isolates. When applied to 48 test strains, the RCA method showed 100\% agreement with DNA sequencing where an $E R G I /$ mutation-specific probe was used. Of 20 different missense mutations detected by sequencing in 24 of $25(96 \%)$ isolates with reduced fluconazole susceptibility, 16 were detected by RCA. Five missense mutations were detected by both methods in 18 of $23(78 \%)$ fluconazole-susceptible strains. DNA sequencing revealed that mutations in non-susceptible isolates were all due to homozygous nucleotide changes. With the exception of the mutations leading to amino acid substitution E266D, those in fluconazole-susceptible strains were heterozygous. Amino acid substitutions common to both sets of isolates were DII6E, E266D, $\mathrm{KI} 28 \mathrm{~T}$, V437I and V488I. Substitutions unique to isolates with reduced fluconazole susceptibility 
were G464 S ( $n=4$ isolates), G448E $(n=3)$, G307S $(n=3), \operatorname{KI} 43 R(n=3)$ and YI23H, S405F and R467K (each $n=1$ ). DNA sequencing revealed a novel substitution, $G 450 V$, in one isolate.

Conclusion: The sensitive RCA assay described here is a simple, robust and rapid ( $2 \mathrm{~h}$ ) method for the detection of ERGII polymorphisms. It showed excellent concordance with ERGII sequencing and is a potentially valuable tool to track the emergence and spread of azole-resistant C. albicans and to study the epidemiology of ERGII mutations. The RCA method is applicable to the study of azole resistance in other fungi.

\section{Background}

Candida albicans causes systemic infections, typically in immunocompromised patients, as well as mucosal infections such as oropharyngeal candidiasis (OPC) in HIVinfected patients and chronic vaginal infections [1,2]. Azole antifungal drugs are the mainstay of management of such infections. However, with increased use of these agents, particularly fluconazole, treatment failures associated with the emergence of azole-resistant strains of $C$. albicans have occurred [3-6] This has been most evident in HIV/AIDS patients receiving long-term therapy for OPC $[3,7]$

The azoles bind to and inhibit the activity of lanosterol $14 \alpha$-demethylase (Erg11p), a key enzyme in the fungal ergosterol biosynthesis pathway [8]. Several mechanisms of resistance to azoles have been described in C. albicans. These include increased expression of the drug efflux pump genes such as MDR1, CDR1 and CDR2 [3,9-11], amino acid substitutions in the target enzyme Erg11p due to missense mutations in the ERG11 gene [3,5,10,12-15] and possibly, overexpression of ERG11 [3,16] Importantly in any one isolate, resistance may be due to a combination of mechanisms $[3-5,15]$.

To date, more than 60 amino acid substitutions have been described in Erg11p with at least 30 of these identified in azole-resistant isolates $[5,12,14-17]$ The impact of individual substitutions, however, varies, and may differ between azoles. For example, substitutions such as Y132H, G450E, G464S, R467K and S405F appear to primarily impact on fluconazole and voriconazole, but not posaconazole, susceptibility $[12,13,16,17]$ The effect of substitutions can also be additive - strains with G129A and G464S substitutions display higher MICs azoles compared with those with the G129A substitution alone [18]. The contributions of yet other ERG11 mutations to resistance are uncertain $[15,19]$. As most strains of C. albicans are diploid, nucleotide mutations may occur as homozygous (in both alleles) or as heterozygous (in one allele) substitutions; the association of either type of mutation with the resistant (or susceptible) phenotype is not well defined $[3,20]$.
Nonetheless, since even single nucleotide polymorphisms (SNPs) in the ERG11 gene can have an impact on susceptibility and contribute to resistance $[5,13,15,18,19,21]$, the documentation of these changes is important. To date, the frequency and clinical relevance of specific mutations in unselected azole-resistant isolates is poorly-defined [17] although in one survey, ERG11 mutations contributed to resistance in $65 \%$ of fluconazole-resistant C. albicans from HIV patients with OPC [5]. In clinical practice, detection of ERG11 mutations as potential markers or comarkers of resistance would assist both the identification and tracking of azole-resistant strains. Traditionally, DNA sequence analysis has been the standard for identifying ERG11 nucleotide changes $[5,14,17,19]$ However, circularisable or padlock probes have recently been shown to reliably detect SNPs with high specificity, offering a rapid simple alternative to sequencing $[22,23]$. Padlock probes comprise three distinct regions: a central linker is flanked by sequences complementary to the $5^{\prime}$ and 3 ' termini of the target sequence. Upon hybridisation to the target, the probe ends are brought together and are joined by DNA ligase to form a closed circular molecule in a highly targetdependent manner (Figure 1). The intensity of the probe signal is then increased exponentially by rolling circle amplification (RCA) generating up to a $10^{9}$-fold signal amplification within 90 min [22-24] RCA-based assays have been successfully used to identify fungal pathogens $[25,26]$ but have not yet been applied to the detection of gene mutations associated with antifungal drug resistance.

The present report describes the development and validation of a sensitive RCA-based SNP detection assay using real time PCR to detect point mutations in the C. albicans ERG11 gene in eight azole-resistant "reference" isolates with known mutations [15]; ERG11 was chosen as the target gene to detect SNPs associated with azole resistance in a proof of principle study. In the study, RCA and DNA sequencing were applied to estimate the frequency of a series of ERG11 mutations and their nature in 25 unselected Australian C. albicans clinical isolates with reduced susceptibility to fluconazole. The results were compared with those obtained for 23 fluconazole-susceptible strains. 


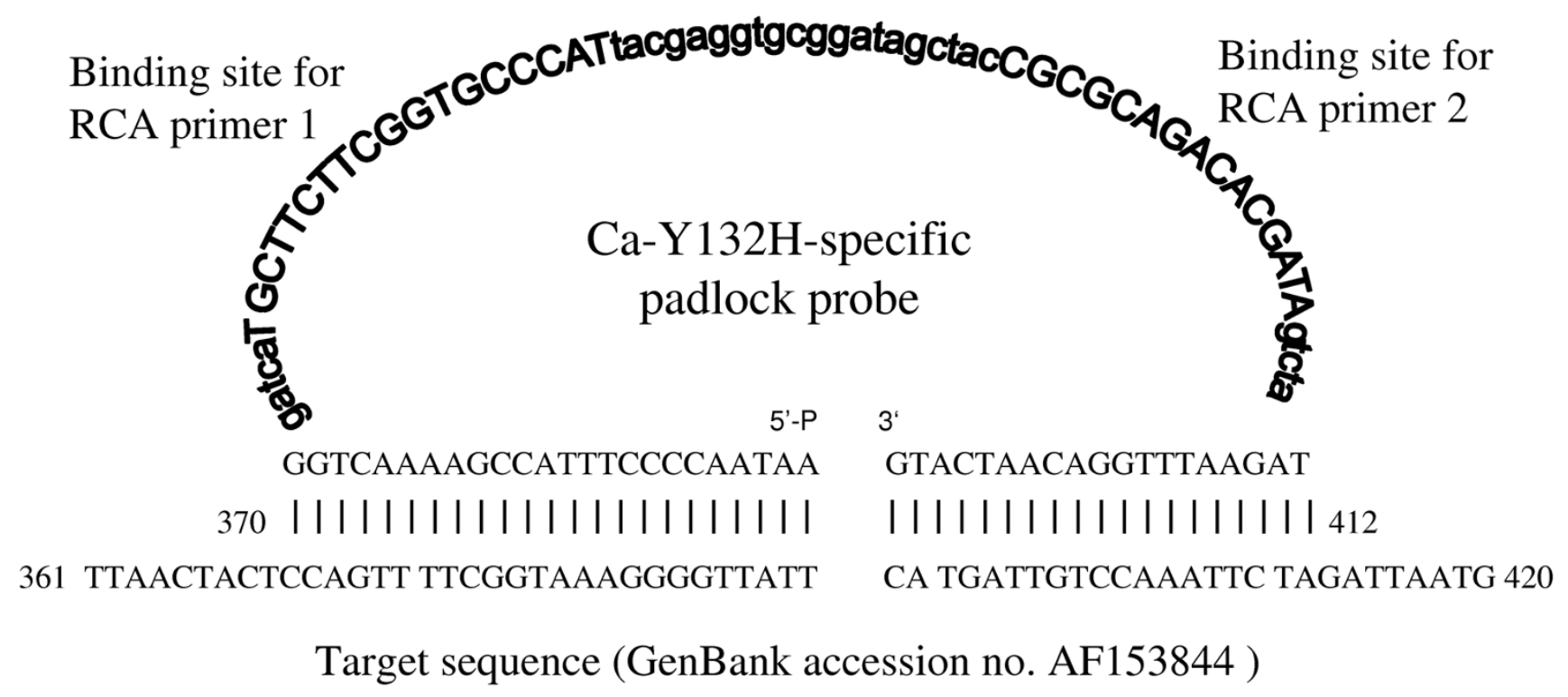

Figure I

Typical design of a circularisable padlock probe. Design and components of a typical padlock probe as exemplified by the $\mathrm{Ca}-\mathrm{Y} I 32 \mathrm{H}$ probe specific for the $\mathrm{Y} \mid 32 \mathrm{H}$ amino acid substitution. The probe comprises (i) a 5'-phosphorylated end; (ii) a "backbone" containing binding sites for the RCA primers (RCA primer I and 2, respectively) designated by bold upper case letters) as well as the non-specific linker regions (designated by bold lower case letters) and (iii) a 3'-end. The 5'- and 3'-ends of the probe are complementary to the $5^{\prime}$ and $3^{\prime}$ termini of the target sequence in reverse, in this example, to the $C$. albicans sequence (GenBank accession no. AFI53844). Abbreviations: 5'-P, 5'-phosphorylated binding arm; 3'-, 3' binding arm.

\section{Results}

\section{C. albicans isolates and azole susceptibilities}

Thirty-three isolates had reduced susceptibility to fluconazole. Twenty-eight were recovered from the oropharynx, two from the vagina and one each from bile, sputum and blood (Tables 1 and 2). The ERG11 gene from eight of these isolates, referred to as "reference" isolates, was previously sequenced (see Methods and Table 1) [15]; the remaining 25 clinical isolates were interrogated for ERG11 mutations (Table 2). An additional 23 fluconazole-susceptible isolates (see Methods for categories of susceptibility/resistance) cultured from a range of body sites (Table 2) were studied. Thus 48 "test" isolates were analysed by RCA and DNA sequencing.

One of the eight "reference" isolates was susceptible-dose dependent (S-DD; MIC 16-32 $\mu \mathrm{g} / \mathrm{ml}$ ) to fluconazole and seven were fluconazole-resistant $(\mathrm{MIC} \geq 64 \mu \mathrm{g} / \mathrm{ml}$; Table

Table I: RCA a analysis of azole-resistant C. albicans isolates with known ERGII mutations ${ }^{\mathrm{b}}$.

\begin{tabular}{|c|c|c|c|c|c|c|}
\hline \multirow[b]{2}{*}{ Patient no. } & \multirow[b]{2}{*}{$\begin{array}{l}\text { Isolate } \\
\text { no. }\end{array}$} & \multirow[b]{2}{*}{$\begin{array}{l}\text { Body site of } \\
\text { isolation }\end{array}$} & \multicolumn{2}{|c|}{ MIC ( $\mu \mathrm{g} / \mathrm{ml})$} & \multirow[b]{2}{*}{$\begin{array}{l}\text { Previously-characterized } \\
\text { amino acid substitution(s) }\end{array}$} & \multirow[b]{2}{*}{$\begin{array}{l}\text { Erg I I p } \\
\text { substitution(s) by RCA }\end{array}$} \\
\hline & & & FLUa & VORa & & \\
\hline \multirow[t]{2}{*}{1} & C438 & Oropharynx & 128 & 2 & Y257H, G464S & Y257H, G464S \\
\hline & $\mathrm{C} 440$ & Oropharynx & $>256$ & $>16$ & A6IV, Y257H, G307S, G464S & A6IV, Y257H, G307S, G464S \\
\hline 2 & C470 & Oropharynx & 32 & 0.25 & S405F & S405F \\
\hline 3 & C480 & Oropharynx & 128 & 8 & G464S, KI28T, R467I & G464S, KI28T, R467I \\
\hline 4 & C507 & Oropharynx & 64 & 8 & G464S, H283R, YI32H & G464S, H283R, YI $32 \mathrm{H}$ \\
\hline 5 & C527 & Oropharynx & 256 & 4 & G450E, YI32H & G450E, YI32H \\
\hline 6 & C577 & Oropharynx & 128 & 0.5 & G464S & G464S \\
\hline 7 & C594 & Oropharynx & 128 & 16 & S405F, YI32H & S405F, YI32H \\
\hline
\end{tabular}

a Abbreviations: RCA, rolling circle amplification; FLU, fluconazole; VOR, voriconazole.

b Chau et al. [15]. 
Table 2: MIC results and Erg I lp substitutions for 25 C. albicans isolates with reduced susceptibility to fluconazole and 23 fluconazolesusceptible isolates by $R C A^{a}$ and $E R G I I$ sequencing.

\begin{tabular}{|c|c|c|c|c|c|c|c|c|c|c|c|c|c|c|c|c|c|c|c|}
\hline & & \multicolumn{2}{|c|}{ MIC ( $\mu \mathrm{g} / \mathrm{ml})$} & \multicolumn{16}{|c|}{ Erg I Ip amino acid substitutions } \\
\hline & & & & D & D & E & $\mathbf{F}$ & $\mathbf{F}$ & G & G & G & G & $\mathbf{K}$ & $\mathbf{K}$ & $\mathbf{R}$ & $\mathbf{S}$ & $\mathbf{v}$ & $\mathbf{v}$ & $\mathbf{Y}$ \\
\hline & & & & $\mathbf{I}$ & 2 & 2 & $\mathbf{I}$ & 4 & 3 & 4 & 4 & 4 & $\mathbf{I}$ & $\mathbf{I}$ & 4 & 4 & 4 & 4 & $\mathbf{I}$ \\
\hline \multirow[t]{3}{*}{ Patient/isolate no. } & Site & FLUa & VOR $^{a}$ & $\mathbf{I}$ & 7 & 6 & 4 & 4 & 0 & 4 & 6 & 6 & 2 & 4 & 6 & 0 & 3 & 8 & 3 \\
\hline & & & & 6 & 8 & 6 & 5 & 9 & 7 & 8 & 4 & 5 & 8 & 3 & 7 & 5 & 7 & 8 & 2 \\
\hline & & & & E & E & D & $\mathbf{L}$ & $\mathbf{S}$ & $\mathbf{S}$ & E & $\mathbf{S}$ & $\mathbf{S}$ & $\mathbf{T}$ & $\mathbf{R}$ & $\mathbf{K}$ & $\mathbf{F}$ & I & I & H \\
\hline
\end{tabular}

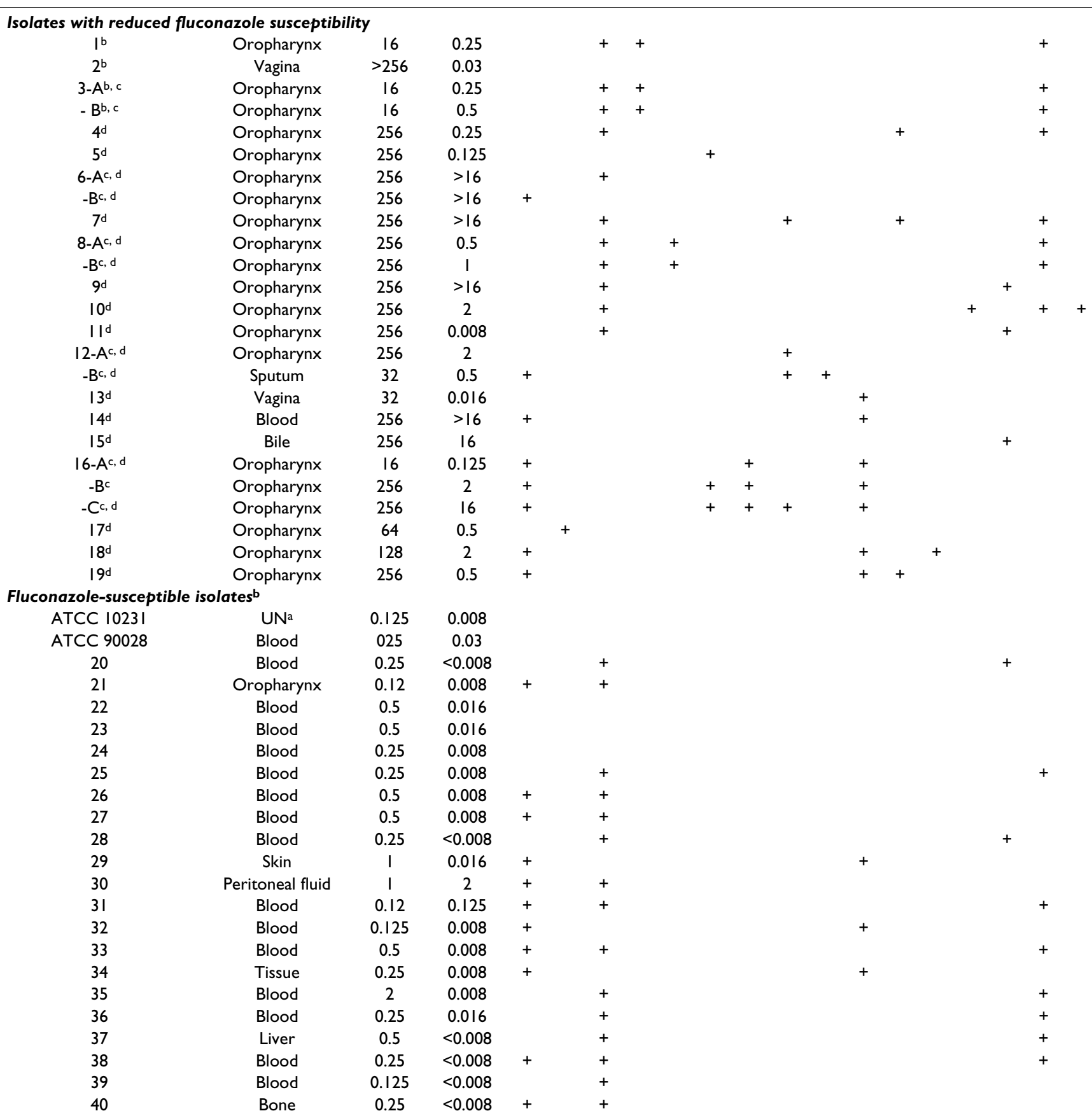

The "+" sign denotes the presence of the mutation.

aAbbreviations: RCA, rolling circle amplification; FLU, fluconazole; VOR, voriconazole; UN, unknown.

b Isolates from the Centre for Infectious Diseases and Microbiology, Westmead Hospital, Sydney.

c The "A" and "B" notation of patient numbers refers to isolates cultured sequentially from the same patient at different times.

dsolates obtained from the Mycology Unit, Women's and Children's Hospital, Adelaide. 
1); five of these seven were also resistant to voriconazole $(\mathrm{MIC} \geq 4 \mu \mathrm{g} / \mathrm{ml})[15,27]$. Six of the 25 Australian isolates (from patients 1, 3, 12, 13 and 16; Table 2) had fluconazole MICs in the S-DD range and were susceptible to voriconazole; the remaining 19 were resistant to fluconazole and seven (from patients 6, 7, 9, 14, 15 and 16) of these were cross-resistant to voriconazole (Table 2). All $23 \mathrm{flu}-$ conazole-susceptible isolates were also susceptible to voriconazole (Table 2).

\section{Detection of ERG I I mutations by RCA: Sensitivity and specificity}

Point mutation-specific RCA probes were designed based on the target polymorphism site of interest in the ERG11 gene (see Additional file 1). To assess the sensitivity of the RCA-based assay, RCA was initially performed on 10-fold serial dilutions of the target template (PCR product; see Methods) ranging from $10^{11}$ to $10^{0}$ copies of template. For all isolates studied, a clear RCA fluorescence signal was observed with a sensitivity of detection of $10^{9}$ copies; below this copy number, the signal was not easily distinguishable from the background signal (as defined when amplifying target template that did not have the mutation of interest) (Figure 2). Only signals that were clearly measurable above background were considered to be indicative of the presence of the mutation.

The capability of the RCA assay to detect heterozygous, as well as homozygous ERG11 nucleotide changes was assessed indirectly by testing its ability to detect a specific mutation in the presence of wild-type template (ie. template without the mutation of interest) using the eight "reference" isolates. For each of the known ERG11 mutations (Table 1$)$, target template $\left(10^{11}\right.$ copies) containing the mutation at $100 \%, 50 \%, 20 \%, 10 \%, 5 \%, 2 \%$ and $0 \%$ concentration in a backdrop of wild-type template were prepared by mixing both templates at the above-mentioned ratios. In all cases, a clear RCA signal above background was observed down to a dilution containing $5 \%$ target template (Figure 3); results were reproducible with minimal or no variation in repeat $(n=3)$ experiments. The results demonstrate that the RCA assay was able to detect ERG11 mutations with high sensitivity in the presence of mixtures of DNA and that the sensitivity was well

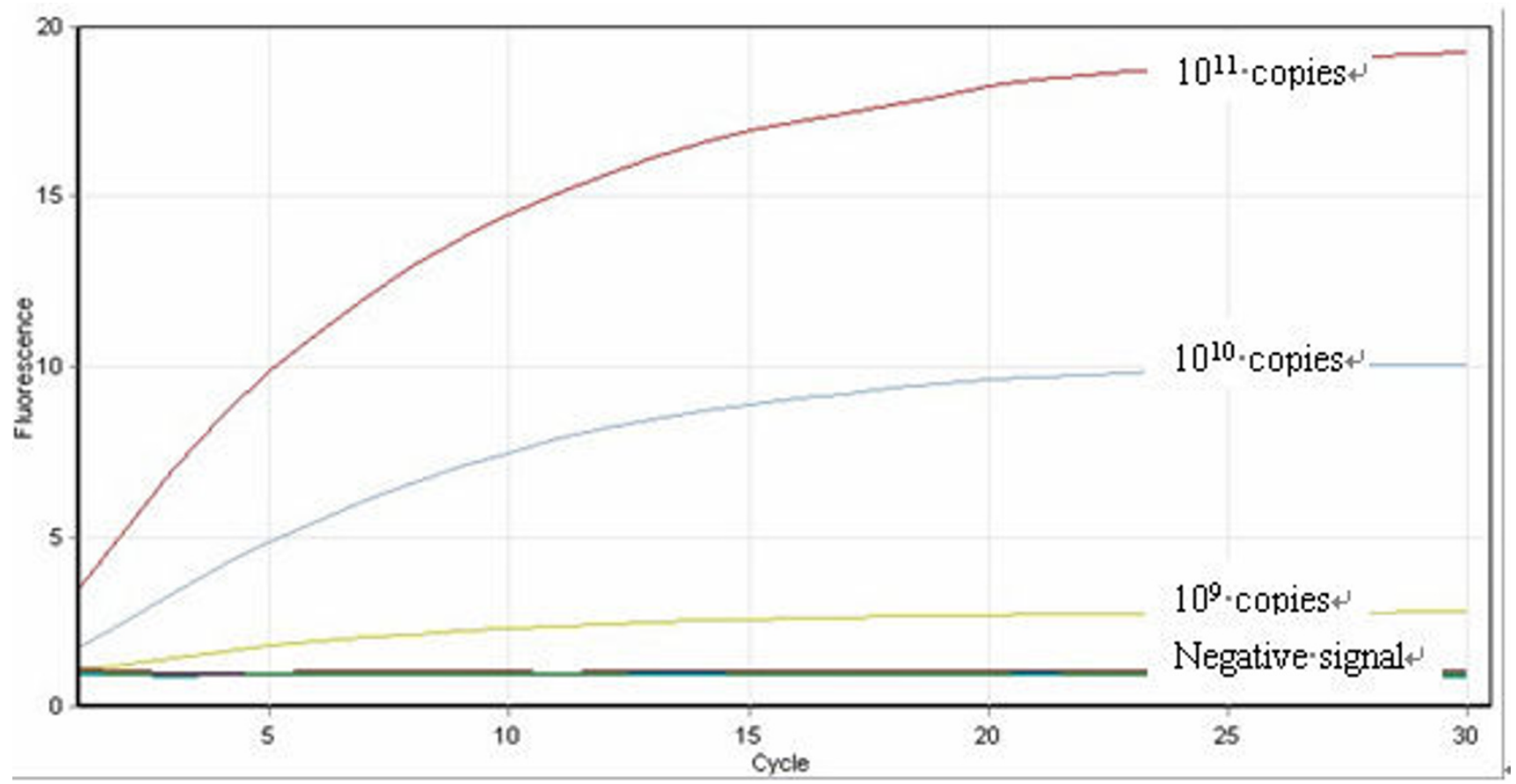

Figure 2

Sensitivity of the RCA assay. RCA was performed on I0-fold serial dilutions of the target template ranging from $10^{11}$ to $10^{\circ}$ copies of target template (PCR product). The figure illustrates the RCA reaction using the Ca-YI32H-specific probe to detect $10^{11}, 10^{10}$ and $10^{9}$ copies of the template containing the $\mathrm{Y} 132 \mathrm{H}$ mutation (obtained from amplifying DNA from isolate C594). RCA signals are shown as exponential increases in florescence signal above baseline (indicated by the "negative signal" label and defined as the signal obtained when amplifying target template that did not have the mutation of interest). The intensity of the signal weakened with decreasing copy numbers starting at $10^{\prime \prime}$ copies and the sensitivity of the assay corresponded to a concentration of $10^{9}$ copies of target template. 
above that required to detect heterozygous nucleotide changes (expected ratio of target template (with mutation) to template without mutation of $1: 1)$ ).

The RCA assay was also highly specific. Amplification of probe signals was seen only with matched template-probe mixtures. No signal was seen when template from isolates that did not contain the ERG11 polymorphism targeted by a specific padlock probe were used. Figure 4 illustrates a typical padlock probe-RCA reaction using a probe to detect the Erg11p Y132H mutation. For isolates C507, C527 and C594 (Table 1), exponential increases in fluorescence signals were readily interpretable, indicating the presence of the Y132H mutation. Other "reference" isolates produced a signal at "background" level, indicative of absence of the mutation. All 10 known ERG11 mutations in the "reference" isolates were correctly identified. The duration of the RCA procedure was $2 \mathrm{~h}$; however, a readily discernible signal was usually evident $15 \mathrm{~min}$ after commencement of the RCA reaction.

\section{Investigation of ERG I I mutations in test isolates by RCA and ERGI I sequencing}

The ERG11 gene for each of the 48 test isolates (25 nonfluconazole susceptible and 23 fluconazole-susceptible) was amplified by PCR and a 1370 bp fragment (nt 1311500) was probed using RCA or subject to DNA sequencing (Table 2).

\section{Isolates with reduced fluconazole susceptibility}

By sequencing, all but one isolate (from patient 2; Table 2 ) contained at least one missense mutation when compared with the C. albicans ATCC 28526 sequence (GenBank accession no. AF153844) (results not shown). Results obtained by the RCA assay were concordant with DNA sequencing for all isolates. However, DNA sequencing identified four additional amino acid substitutions (D153E, F126L, K108E and a novel substitution G450V) in six separate isolates (from patients 5, 6, 10, 11 and 12 as shown in Table 3) - these substitutions were not detected by RCA as the corresponding padlock probes tar-

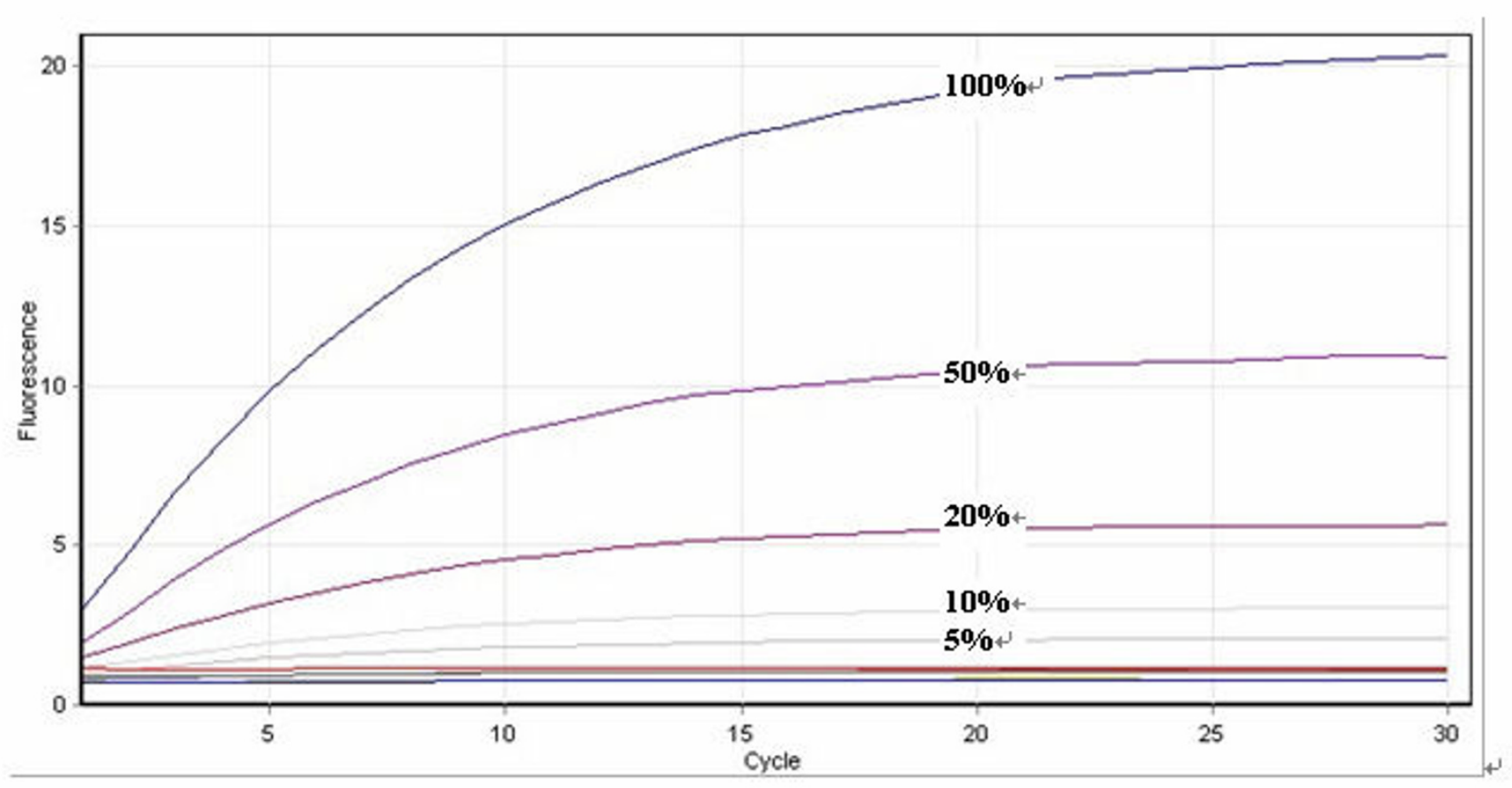

Figure 3

Sensitivity of the RCA assay in the presence of DNA mixtures. The accumulation of double-stranded DNA was detected by staining with Sybr green I. RCA signals indicative of the presence of a specific mutation are shown as exponential increases in fluorescence signal above baseline. The figure illustrates the padlock probe-RCA reaction using the Ca-Y257H-specific probe to detect varying concentrations (100\%, 50\%, 20\%, 10\% and 5\%) of target template (I0'Icopies). The target template was DNA from isolate C594 containing the Y257H mutation; this was diluted with DNA from strain ATCC I023 I (without the $\mathrm{Y} 257 \mathrm{H}$ mutation). The intensity of RCA fluorescence signal weakened with decreased template concentration. The sensitivity of the assay corresponded to a concentration of $5 \%$ template DNA in the mixture. 


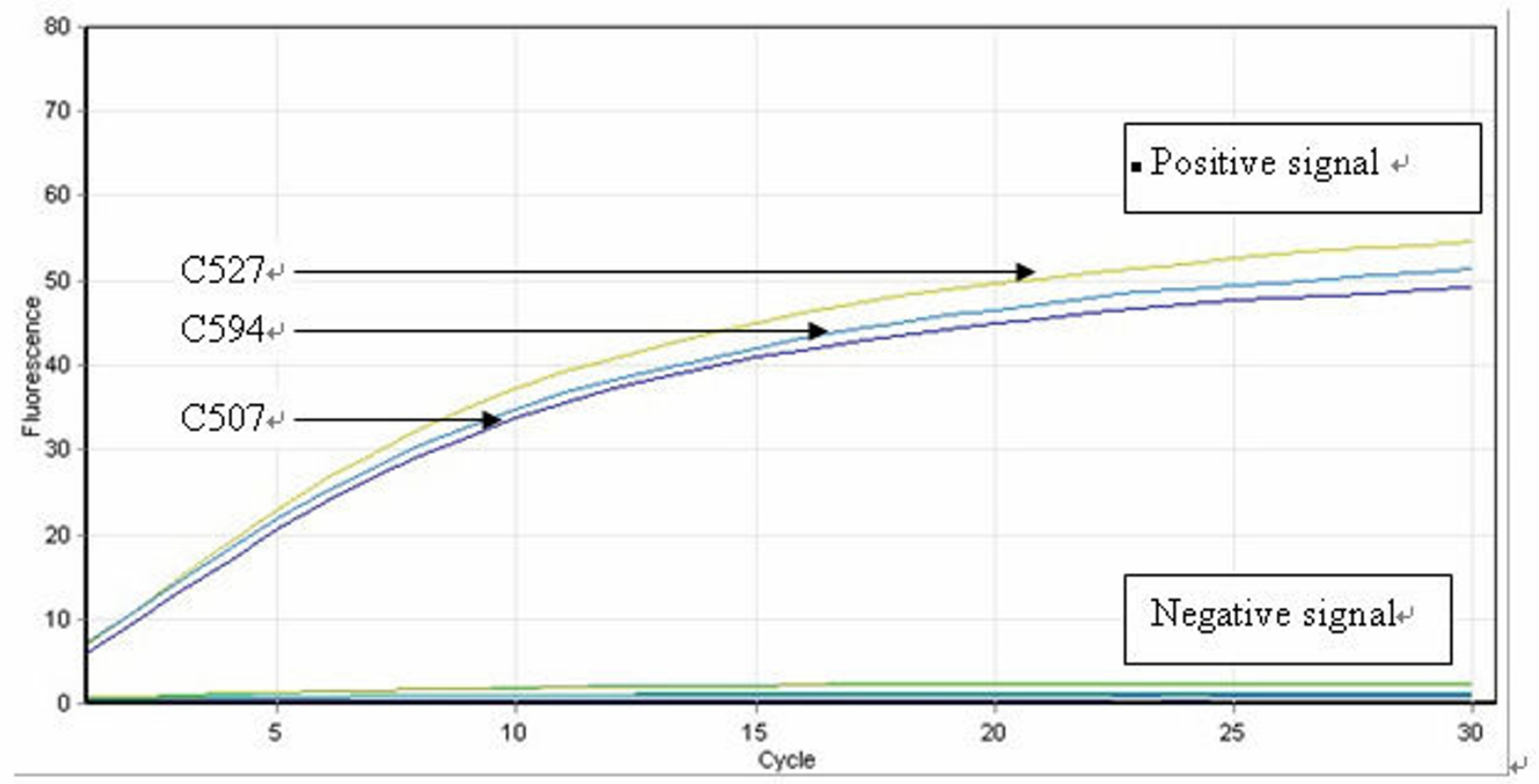

\section{Figure 4}

Specificity of the RCA assay. RCA results monitored by the RotorGene 6000 real-time PCR machine (Corbett research). The accumulation of double-stranded DNA was detected by staining with Sybr Green I. RCA signals indicating the presence of the mutation of interest ((labeled as "positive signal") are shown as exponential increases in fluorescence. The experiment was conducted using the Ca-YI32H-specific RCA probe and tested on eight $C$. albicans isolates with known ERGI I mutation sites (Table I). Ligation-mediated RCA with matched templates (DNA from isolates C527, C594, C507) containing the targeted SNPs produced "positive signals". Other templates showed an absence of signal (labeled as "negative signal").

geting these mutation sites were not used in the study. Thus ERG11 point mutations resulting in 16 different amino acid substitutions were detected among the 25 test isolates by RCA (Table 2) whereas 20 substitutions were identified by DNA sequencing. Sequencing identified that all amino acid substitutions were due to homozygous nucleotide polymorphisms.

The substitution G464S was present in four isolates, G448E and G307S were present in three isolates each and the substitutions Y132H, S405F and R467K (each n = 1) were rare (Table 2). Of note, five of the 10 ERG11 mutations (leading to amino acid substitutions A61V, G450E, H238R, R467I and Y257H) present in "reference" isolates from the United States (Table 1) were not detected in Australian isolates. Overall, the most frequently-identified substitutions were E266D ( $\mathrm{n}=11$ isolates) followed by V488I $(\mathrm{n}=8)$, D116E $(\mathrm{n}=8)$ and K128T $(\mathrm{n}=7)$. Nineteen of the 20 mutations (95\%) were clustered in three regions of Erg11p: positions 105-165, 266-287 and 405-488 (Table 2).

Table 3: Additional amino acid substitutions identified by ERG I I sequencing in five C. albicans isolates with reduced susceptibility to fluconazole.

\begin{tabular}{ccc}
\hline Patient/isolate no. & Substitutions detected by RCA & Substitutions detected by DNA sequencing \\
\hline 5 & G307S & G307S, G450V \\
$6-A^{a}$ & E266D & E266D, DI53E \\
$6-B^{a}$ & DII6E & DII6E, DI53E \\
10 & E266D, V488I, S405F, YI32H & E266D, V488I, S405F, YI32H, KI08E \\
$I I$ & E266D, V437I, FI26L \\
\hline $12-\mathrm{A}^{\mathrm{a}}$ & $\mathrm{G} 464 \mathrm{~S}$ & $\mathrm{G} 464 \mathrm{~S}, \mathrm{KI} 108 \mathrm{E}$ \\
\hline
\end{tabular}

\footnotetext{
a The "A" and "B" notation of patient numbers refers to isolates which were cultured sequentially from the same patient at different times.
} 
Sequential isolates were available from five patients (patients 3 6, 8, 12 and 16). Isolates from patients 3 and 8 had similar ERG11 mutation and MIC profiles; however, isolates from patient 16 demonstrated a step-wise increase in voriconazole MICs in parallel with additional amino acid substitutions; the isolate with the highest MIC contained five substitutions while the isolate with the lowest MIC contained three (Table 2). Conversely, for patient 12 , one additional mutation was present from the analysis of the second isolate (isolate 12B; see also Table 3 ) but the fluconazole and voriconazole MICs of this isolate were lower than that for isolate 12A. Both isolates from patient 6 had similar azole MICs but had one different ERG11 mutation (Tables 2 and Table 3).

\section{Fluconazole-susceptible isolates}

No ERG11 mutations were detected by either RCA or ERG11 sequencing in five of the 23 (22\%) fluconazolesusceptible isolates. In the other 18 , five amino acid substitutions namely E266D ( $\mathrm{n}=15$ isolates), D116E ( $\mathrm{n}=$ $11)$, V488I $(\mathrm{n}=7), \operatorname{K128T}(\mathrm{n}=3)$ and V437I $(\mathrm{n}=2)$ were identified (Table 2). By sequencing, homozygous nucleotide changes that led to the E266 substitution were present in all isolates; for the remaining amino acid substitutions, nucleotide mutations were heterozygous. In all cases, RCA results were concordant with those obtained by DNA sequencing confirming that the RCA-based assay is capable of detecting both homozygous and heterozygous SNP substitutions in ERG11.

\section{Mutations unique to isolates with reduced fluconazole susceptibility}

Fifteen of the $20 \operatorname{Erg} 11 \mathrm{p}$ amino acid substitutions present in C. albicans isolates displaying S-DD susceptibility or resistance to fluconazole were not identified in fluconazole-susceptible strains (Table 2). These included the substitutions G307S, G464S, G448E R467K, S405F and $\mathrm{Y} 132 \mathrm{H}$ which have been reported to result in reduced susceptibility to azoles $[5,10,15]$

\section{Discussion}

Azole antifungals are widely used for therapy and prophylaxis of Candida infections. A better understanding of the mechanisms of resistance to these agents as well as early detection of resistance are essential for patient management. Azole resistance is often due to a combination of factors including increased expression of efflux pumps and missense mutations in ERG11 [3-5,15]. The latter have been linked to clinically-relevant increases in the MICs, not only to fluconazole, but also to the newer azoles voriconazole and posaconazole $[4,5,10,15]$ This proof of principle study highlights the great potential of a simple rapid $(2 \mathrm{~h})$ and highly-specific RCA-based SNP detection assay that can be readily be performed in the clinical laboratory for the detection and/or surveillance for ERG11 mutations. Using this method, we identified Erg11p amino acid substitutions in 24 of 25 previouslyuncharacterised Australian isolates with reduced susceptibility to fluconazole.

The sensitivity and reproducibility of the RCA assay was established by determining its ability to detect known ERG11 mutations in "reference" isolates (Table 1) in comparison with DNA sequencing. The padlock probes designed for this study also accurately identified and distinguished between SNPs within the ERG11 genes in the test isolates. These included SNPs that were located close together such as those at nucleotides 1343, 1346 and 1349 corresponding to the amino acid substitutions G448E, F449S and G450E, respectively (Additional file 1). Importantly, identification of ERG11 mutations by the RCA assay was concordant with sequencing in all cases where an ERG11 mutation-specific probe was used. An additional finding was that even though probes (or pairs of probes) were not designed to detect heterozygous nucleotide substitutions per se, the RCA assay detected such changes in isolates containing an ERG11 mutation in only one allele, as demonstrated by their identification in fluconazole-susceptible isolates.

A large number $(\mathrm{n}=20)$ of amino acid substitutions were identified in test isolates with reduced susceptibility/ resistance to fluconazole. In agreement with a prior report, all but one isolate had at least one, and often multiple missense mutations in ERG11 [15]. Substitutions also varied widely between individual isolates. Similar results have been reported by Perea et al. who detected 13 ERG11 mutations in 20 C. albicans isolates with high level fluconazole resistance of which 11 were linked to resistance [5]. In contrast, just a single ERG11 mutation profile (comprising the same two mutations) was found in 14 of 15 fluconazole-resistant isolates in another study [17].

To our knowledge the G450V amino acid substitution has not been previously identified among isolates with reduced susceptibility to azoles. Most of the other substitutions described here have previously been seen in azoleresistant isolates $[5,15,17,20]$ In particular, the substitutions G464S, G307S and G448E, known to confer azole resistance $[5,12,15]$, were identified in three or more isolates. However, it is notable that the substitutions $\mathrm{Y} 132 \mathrm{H}$, S405F and R467K which appear to be prevalent in the United States and Europe were rare in Australian isolates $[5,12,13,15]$. Nineteen of the 20 amino acid substitutions, including G450V, present in the test isolates were clustered into the three "hot-spot" regions as described previously [19]. These hot spots include the residues 105165 near the N-terminus of the protein, region 266-287 and region 405-488 located towards the $\mathrm{C}$ terminus of the protein. The exception was the G307S substitution (n 
$=3$ isolates). However, in a computer-generated model of Erg11p, G307S is located close to the heme cofactor binding site. As such, substitutions at this residue might be expected to impact negatively on the binding of the azole [28].

In contrast to the fluconazole-resistant strains described above, $22 \%$ of fluconazole-susceptible isolates contained no ERG11 mutations and of those that did, substantially fewer (five compared with 20) amino acid substitutions were detected. Also of interest, all Erg11p amino acid substitutions from isolates with reduced azole susceptibility phenotypes were homozygous whereas with one exception (E266D), those in fluconazole-susceptible isolates were present as heterozygous substitutions. While these two observations support the general notion that ERG11 mutations are linked to azole resistance, the presence of ERG11 mutations in susceptible isolates is not readily explained. Development of "resistance" requires prolonged exposure to an azole [3,4]; however previous studies have not attempted to relate mutations in susceptible isolates to fluconazole exposure. Due to the retrospective nature of the present study we were unable to test this association.

The limitations of this study are recognised. Given the small numbers of isolates in our collection and that the presence of ERG11 mutations are not necessarily functionally related to resistance, we were unable to determine the clinical relevance of the ERG11 mutations identified. Since the substitutions E266D, D116E and V347I were present in both fluconazole-susceptible and, resistant isolates, it could be argued that they are unlikely to have contributed to reduced azole susceptibility $[5,12,17,19]$. On the other hand, with one exception, all identified mutations were heterozygous in fluconazole-susceptible isolates; the finding supports the contention that loss of heterozygosity in a diploid species such as C. albicans is a step in the development of the azole-resistant phenotype $[3,20,29]$. It is also possible that many ERG11 polymorphisms whilst not conferring resistance per se, may play a role in increasing the level of resistance $[12,21]$.

Conversely, the absence of substitutions G307S, G448E, G464S, Y132H, S405F and R467K, in susceptible isolates strongly suggests they have contributed to the resistant phenotype. This hypothesis can be tested by site-directed mutagenesis and expression studies of specific ERG11 alleles in Saccharomyces cerevisiae. Using this approach, Sanglard and co-workers demonstrated that the substitutions G464S, Y132H, S405F and R467K were linked to azole resistance among their collection of isolates [12]; similar studies are warranted to determine if the new substitution G450V is associated with resistance. Testing matched, susceptible and resistant, isolates from the same patient for ERG11 mutations may also assist in determining if particular mutations impact on azole resistance; unfortunately, matched isolates were not available in the present study. In general, neither the type or number of mutations in isolates sequentially obtained from the same patient correlated with azole MICs (Table 2), emphasising the need to assess additional genes to understand the contribution of each to the resistance phenotype. As such, methods that detect polymorphisms are well-placed to screen large numbers of isolates from different sources for mutations and to guide functional testing of these isolates for resistance.

This study demonstrates a new application of a simple RCA-based technique for the rapid and accurate detection of SNPs in the ERG11 gene as potential markers of resistance and for the tracking of resistant strains. Other sequencing-independent methods include conventional real time PCR and/or other probe-based technologies eg. molecular beacons or TaqMan probes [30,31]. Results using conventional real time PCR are well-known to be highly-dependent on the physical characteristics of the platform. Molecular beacons and TaqMan probe methods are conveniently available in the form of commercial kits. Although able to detect SNPs with good sensitivity $[30,31]$, strict attention to the Tm of the probes is required to ensure adequate specificity. The RCA-based method described here offers several advantages over other amplification techniques in that ligation of the probe ends by DNA ligase requires perfectly-matched target-probe complexes preventing nonspecific amplification generated by conventional PCR and resulting in very high specificity. It is also rapid ( $2 \mathrm{~h}$ compared to 1-2 days for DNA sequencing following DNA extraction). Whilst the set-up costs of the assay are relatively high, (AUD 300 per probe), a typical commercial batch of each probe provides sufficient material for up to 5000 assays. Running costs are estimated at no more than AUD 2 per assay compared to AUD 15 for DNA sequencing. The limitations of RCA in the primary identification of resistance are acknowledged (see above). However, the technique is well-suited as an epidemiological tool for high throughput screening for commonly-encountered ERG11 SNPs to assist in the detection of potentially-resistant strains and to track the movement of such strains. Further, its utility in detecting SNPs in other genes that have been linked to azole resistance in $C$. albcians such as those encoding for the transcriptional activator of CDR1 (TAC1) and the transcriptional activator Upc2 (UPC2) [32,33] warrant consideration.

\section{Conclusion}

In conclusion, the sensitive and specific RCA-based assay proved to be a simple robust method for the rapid detection of ERG11 mutations and showed excellent concord- 
ance with DNA sequencing. It has good potential as a tool for tracking specific strains and identifying markers/comarkers of azole resistance. Broader implications include application of the method in the study of oher gene mutations linked to azole resistance in C. albicans and of azole resistance in other fungi such as Aspergillus fumigatus in which ERG11 mutations are a major mechanism of resistance $[34,35]$.

\section{Methods}

\section{C. albicans isolates}

Eight fluconazole-resistant "reference" isolates with previously-described mutations in ERG11 (strains C438, C440, C470, C480, C507, C527, C577 and C594 provided by A. Chau, Schering-Plough Research Institute, Kenilworth, New Jersey; Table 1) [15] were used to validate the RCA assay. Two fluconazole-susceptible isolates (strains ATCC 10231 and ATCC 90028) were purchased from the American type culture collection (ATCC; Rockville, Md). Of 46 Australian clinical C. albicans isolates, 25 (obtained from 19 patients) were resistant, or had reduced susceptibility to fluconazole (five patients - patient 3, 6, 8, 12 and 16 had $>1$ isolate recovered on separate occasions) and 21 were fluconazole-susceptible (Table 2). These isolates were from the culture collection of the Clinical Mycology laboratory, Westmead Hospital, Sydney and the Mycology Unit, Women's and Children's Hospital, Adelaide. The experimental work was approved as part of a Centre of Clinical Research Excellence Grant awarded by the National Health and Medical Research Council of Australia (grant \#264625) and approved by the Scientific Advisory Committee, Sydney West Area Health Service and the Research and Development Committee, Centre for Infectious Diseases and Microbiology Laboratory Services, Westmead Hospital. Thus, 33 isolates with reduced fluconazole susceptibility and 23 fluconazole-susceptible isolates were studied. Isolates were identified as C. albicans by standard phenotypic methods [36] and maintained on Sabouraud's dextrose agar at $4{ }^{\circ} \mathrm{C}$ until required.

\section{Broth microdilution susceptibility testing}

MICs of fluconazole and voriconazole (Pfizer Australia, Ryde, Australia) were determined for the ATCC and Australian study isolates (total $\mathrm{n}=48$ ) by broth microdilution using the Clinical and Laboratory Standards Institute (CLSI) M27-A2 protocol for susceptibility testing of yeasts [37]. Candida parapsilosis ATCC 22019 and Candida krusei ATCC 6528 were the quality control strains for each test run. The MIC endpoint was the lowest concentration of drug resulting in 50\% growth inhibition compared with growth in the control (drug-free) well. Isolates were categorised as susceptible (MIC $\leq 8 \mu \mathrm{g} / \mathrm{ml}$ ), susceptible dosedependent (S-DD; MIC $16-32 \mu \mathrm{g} / \mathrm{ml}$ ) or resistant (MIC $\geq$ $64 \mu \mathrm{g} / \mathrm{ml}$ ) to fluconazole according to CLSI methodology [37]. Fluconazole and voriconazole MICs for the "reference isolates" have been reported [15] (Table 1).

\section{DNA extraction and PCR amplification of the ERG I I gene} DNA extraction was performed as described previously [38]. The near-full length ERG11 gene (1480 bp) was amplified with primers ERG11-S (5' aggggttccatttgtttaca $\left.3^{\prime}\right)$ and ERG11-A (5' ccaaatgatttctgctggtt 3'; Beijing AUGCT Biotechnology Co. Ltd., Beijing, China) preparatory to hybridization with padlock probes and subsequent RCA (all isolates; see below) and for ERG11 sequence analysis (ATCC and Australian isolates).

Each PCR reaction contained: $1.5 \mu \mathrm{l}(12-15 \mathrm{ng} / \mu \mathrm{l})$ template DNA, $0.25 \mu \mathrm{l}(50 \mathrm{pmol} / \mu \mathrm{l})$ each of forward primer and reverse primer, $1.25 \mu \mathrm{ldNTPs}(2.5 \mathrm{mM}$ of each dNTP; [Roche Diagnostics, Mannheim, Germany]), $0.1 \mu \mathrm{l} \mathrm{Hot}-$ Star Taq polymerase (5 units/ $\mu \mathrm{l}$ ), $2.5 \mu \mathrm{l} 10 \times$ PCR buffer, (Qiagen, Doncaster, Victoria, Australia) and water to a total volume of $25 \mu \mathrm{l}$. Amplification was performed on a Mastercycler gradient thermocycler (Eppendorf AG, North Ryde, Australia). The thermal cycling conditions were $95^{\circ} \mathrm{C}$ for $15 \mathrm{~min}$, followed by 35 cycles of $94^{\circ} \mathrm{C}$ for $45 \mathrm{~s}$, $58^{\circ} \mathrm{C}$ for $45 \mathrm{~s}$, and $72^{\circ} \mathrm{C}$ for $90 \mathrm{~s}$, with a final extension step at $72^{\circ} \mathrm{C}$ for $10 \mathrm{~min}$. PCR product was visualised under UV illumination to verify amplicon quantity prior to sequence analysis or RCA.

\section{ERGII sequence analysis}

PCR products were purified using the PCR Product Presequencing Kit (USB Corporation, Cleveland, Ohio USA) and sequenced using ERG11-S and ERG11-A primers, and the BigDye Terminator (version 3.1) cycle sequencing kit in the ABI PRISM 3100 genetic analyser (Applied Biosystems, Foster City, CA). Sequences were entered into a BLASTn sequence analysis search and analyzed using editing and analyses programs in the BioManager (ANGIS) facility (accessed via. http://angis.org.au/).

\section{Primer and padlock probe design}

The ERG11 sequence of the azole-susceptible strain $C$. albicans ATCC 28526 as published by Marichal et al. (GenBank database accession no. AF153844) was used for probe design. This sequence was chosen because C. albicans ATCC 28526 has been extensively characterised. A total of 24 padlock probes targeting 24 different ERG11 mutation sites were designed (Additional file 1). Ten of the 24 probes were designed to detect 10 mutations present in the "reference" isolates (Table 1); the remaining 14 targeted additional ERG11 mutations which have been identified in azole-resistant isolates $[5,10,15,19]$.

The probes were 106-123 nucleotides (nt) in length, consisting of two adjacent target complementary sequences with a $48 \mathrm{nt}$ linker region (Figure 1). To optimise binding to target DNA, probes were designed with a minimum of secondary structure and with a Tm of the 5'-end probe binding arm greater than the temperature used for probe ligation $\left(62^{\circ} \mathrm{C}\right.$; see below $)$. To increase the specificity, the 
3 '-end binding arm was designed to have a $\operatorname{Tm}\left(51-56^{\circ} \mathrm{C}\right)$ below the ligation temperature [25]. In particular, careful attention was paid to the linker region for each point mutation-specific probe to (i) minimise similarity to those mutations closely-located to the mutation of interest and (ii) to allow primer binding during RCA and amplification of the probe-specific signal. The 2 primers used for RCA - RCA primer 1 (5' ATGGGCACCGAAGAAGCA 3', Tm $55^{\circ} \mathrm{C}$ ) and RCA primer 2 (5' CGCGCAGACACGATA $3{ }^{\prime}, \operatorname{Tm} 55^{\circ} \mathrm{C}$ ) - were designed to specifically bind the linker region of the probes (Additional file 1)

\section{Purification of RCA template}

Prior to ligation of the probe, ERG11 PCR products were purified to remove excess buffer, dNTP and primers: $25 \mu \mathrm{l}$ of the PCR product was added to a well of a Millipore PCR purification plate (Pall Life Sciences, Ann Arbor, MI, USA) which was then placed on a vacuum manifold for 10-20 min to draw fluid and small particles through the membrane, leaving DNA on top of the membrane. A further 25 $\mu \mathrm{l}$ of $\mathrm{dH}_{2} \mathrm{O}$ was added to the well and the process repeated. The plate was removed from the vacuum, $20 \mu \mathrm{l}$ of $\mathrm{dH}_{2} \mathrm{O}$ was added and the mixture incubated at $25^{\circ} \mathrm{C}$ for 2 min before transferring to a clean Eppendorf tube. Purified PCR products were stored at $4^{\circ} \mathrm{C}$.

\section{Ligation of padlock probe and exonucleolysis}

Purified amplified PCR product (10 11 copy numbers of DNA template [DNA calculator; http://www.uri.edu/ research/gsc/resources/cndna.html]) was mixed with $2 \mathrm{U}$ of Pfu DNA ligase (Stratagene, La Jolla, CA, USA) and 0.1 $\mu \mathrm{M}$ padlock probe as previously described [25] and subjected to multiple cycle ligation comprising one cycle of denaturation at $94^{\circ} \mathrm{C}$ for $5 \mathrm{~min}$, followed by five cycles at $94^{\circ} \mathrm{C}$ for $30 \mathrm{~s}$ and $4 \mathrm{~min}$ of ligation at $62^{\circ} \mathrm{C}$. Exonucleolysis was then performed to remove unligated probe and template PCR product; the purpose of the last step is to reduce subsequent ligation-independent amplification events during RCA. It was performed in $20-\mu$ l volumes by adding $10 \mathrm{U}$ each of exonuclease I and exonuclease III (New England Biolabs, UK) to the ligation mixture and incubating at $37^{\circ} \mathrm{C}$ for $60 \mathrm{~min}$ followed by $95^{\circ} \mathrm{C}$ for 3 $\min$.

\section{RCA}

After exonucleolysis, RCA reactions was performed in 50 $\mu$ l volumes containing $8 \mathrm{U}$ of Bst DNA polymerase (New England Biolabs), $400 \mu \mathrm{M}$ deoxynucleotide triphosphate mix, 10 pmol of each RCA primer, $5 \%$ of dimethyl sulfoxide $(\mathrm{v} / \mathrm{v})$ and $10 \times$ SYBR Green I (Sigma-Aldrich, Castle Hill, Australia). Probe signals were amplified by incubation at $65^{\circ} \mathrm{C}$ for $30 \mathrm{~min}$ and the accumulation of dsDNA products were monitored using a Corbett RotorGeneTM 6000 real-time PCR machine (Corbett Research, Mortlake, Australia). Probe signals were also visualised on a $1.5 \%$ agarose gel to verify the specificity of probe-template binding.

\section{Nucleotide sequence accession numbers}

The ERG11 sequences of the study isolates have been deposited in the GenBank database with the following accession numbers: FJ159508, FJ159444 to FJ159507 inclusive and FJ232378 to $\underline{\mathrm{FJ} 232396}$ inclusive.

\section{Authors' contributions}

SCAC, FK, TCS and HW designed the research. HW and BW carried out the molecular work and sequence alignment. MX participated in the sequence alignment. NP, FW and DE carried out the microbiological identification and susceptibility experiments. PM helped draft the manuscript and performed the susceptibility work on the "reference" isolates. HW, FK, TCS, FW and SCAC wrote the manuscript. All authors approved the final version of the manuscript.

\section{Additional material}

\section{Additional file 1}

Padlock probes and primers used for RCA. The data provide the names and sequences of the probes and primers used in the study for RCA. Click here for file

[http://www.biomedcentral.com/content/supplementary/14712180-9-167-S1.doc]

\section{Acknowledgements}

We thank Rosemary Handke for assistance with the susceptibility testing of the isolates from the Women's and Children's Hospital, Adelaide, OkCha Lee for help with the culture-based identification of $C$. albicans and Maryann Princevic for her assistance in sequencing. This study was supported by a Centre for Clinical Research Excellence Grant (grant \# 264625) from the National Health and Medical Research Council of Australia to TCS.

\section{References}

I. Eggimann P, Garbino J, Pittet D: Epidemiology of Candida species infections in critically ill non-immunosuppressed patients. Lancet Infect Dis 2003, 3:685-702.

2. Odds FC, Webster CE, Mayuranathan P, Simmons PD: Candida concentrations in the vagina and their association with signs and symptoms of vaginal candidosis. J Med Vet Mycol 1988, 26:277-283.

3. White TC, Marr KA, Bowden RA: Clinical, cellular, and molecular factors that contribute to antifungal drug resistance. Clin Microbiol Rev 1998, I I:382-402.

4. Morschhauser J: The genetic basis of fluconazole resistance development in Candida albicans. Biochim Biophys Acta 2002, I 587:240-248.

5. Perea S, Lopez-Ribot JL, Kirkpatrick WR, McAtee RK, Santillan RA, Martinez M, Calabrese D, Sanglard D, Patterson TF: Prevalence of molecular mechanisms of resistance to azole antifungal agents in Candida albicans strains displaying high-level fluconazole resistance isolated from human immunodeficiency virus-infected patients. Antimicrob Agents Chemother 200I, 45:2676-2684.

6. Rex JH, Rinaldi MG, Pfaller MA: Resistance of Candida species to fluconazole. Antimicrob Agents Chemother 1995, 39:1-8. 
7. Lopez-Ribot JL, McAtee RK, Lee LN, Kirkpatrick WR, White TC, Sanglard D, Patterson TF: Distinct patterns of gene expression associated with development of fluconazole resistance in serial Candida albicans isolates from human immunodeficiency virus-infected patients with oropharyngeal candidiasis. Antimicrob Agents Chemother 1998, 42:2932-2937.

8. Kelly SL, Arnoldi A, Kelly DE: Molecular genetic analysis of azole antifungal mode of action. Biochem Soc Trans 1993, 2 I:1034-1038.

9. Franz R, Kelly SL, Lamb DC, Kelly DE, Ruhnke M, Morschhauser J: Multiple molecular mechanisms contribute to a stepwise development of fluconazole resistance in clinical Candida albicans strains. Antimicrob Agents Chemother 1998, 42:3065-3072.

10. Sanglard D, Odds FC: Resistance of Candida species to antifungal agents: molecular mechanisms and clinical consequences. Lancet Infect Dis 2002, 2:73-85.

I I. White TC: Increased mRNA levels of ERG I 6, CDR, and MDR I correlate with increases in azole resistance in Candida albicans isolates from a patient infected with human immunodeficiency virus. Antimicrob Agents Chemother 1997, 4I:| 482-I 487.

12. Sanglard D, Ischer F, Koymans L, Bille J: Amino acid substitutions in the cytochrome P-450 lanosterol I4alpha-demethylase (CYP5IAI) from azole-resistant Candida albicans clinical isolates contribute to resistance to azole antifungal agents. Antimicrob Agents Chemother 1998, 42:241-253.

13. White TC: The presence of an $\mathbf{R} 467 \mathrm{~K}$ amino acid substitution and loss of allelic variation correlate with an azole-resistant lanosterol I 4alpha demethylase in Candida albicans. Antimicrob Agents Chemother 1997, 4 I: I488-1494.

14. Favre $B$, Didmon $M$, Ryder NS: Multiple amino acid substitutions in lanosterol I4alpha-demethylase contribute to azole resistance in Candida albicans. Microbiology 1999, | 45:27| 5-2725.

15. Chau AS, Mendrick CA, Sabatelli FJ, Loebenberg D, McNicholas PM: Application of real-time quantitative PCR to molecular analysis of Candida albicans strains exhibiting reduced susceptibility to azoles. Antimicrob Agents Chemother 2004, 48:2 I 24-2 I 3 I.

16. White TC, Holleman S, Dy F, Mirels LF, Stevens DA: Resistance mechanisms in clinical isolates of Candida albicans. Antimicrob Agents Chemother 2002, 46: I704-1713.

17. Xu Y, Chen L, Li C: Susceptibility of clinical isolates of Candida species to fluconazole and detection of Candida albicans ERG I I mutations. J Antimicrob Chemother 2008, 6 I:798-804.

18. Lamb DC, Kelly DE, Schunck WH, Shyadehi AZ, Akhtar M, Lowe DJ, Baldwin BC, Kelly SL: The mutation T3 I5A in Candida albicans sterol I 4alpha-demethylase causes reduced enzyme activity and fluconazole resistance through reduced affinity. I Biol Chem 1997, 272:5682-5688.

19. Marichal P, Koymans L, Willemsens S, Bellens D, Verhasselt P, Luyten W, Borgers M, Ramaekers FC, Odds FC, Bossche HV: Contribution of mutations in the cytochrome P450 I4alpha-demethylase (Erg I Ip, Cyp5Ip) to azole resistance in Candida albicans. Microbiology 1999, 145:2701-27।3.

20. Lee MK, Williams LE, Warnock DW, Arthington-Skaggs BA: Drug resistance genes and trailing growth in Candida albicans isolates. A Antimicrob Chemother 2004, 53:217-224.

21. Akins RA: An update on antifungal targets and mechanisms of resistance in Candida albicans. Med Mycol 2005, 43:285-318.

22. Nilsson M: Lock and roll: single-molecule genotyping in situ using padlock probes and rolling-circle amplification. Histochem Cell Biol 2006, I 26: 159-164.

23. Nilsson M, Dahl F, Larsson C, Gullberg M, Stenberg J: Analyzing genes using closing and replicating circles. Trends Biotechnol 2006, 24:83-88.

24. Wang B, Potter SJ, Lin Y, Cunningham AL, Dwyer DE, Su Y, Ma X, Hou $Y$, Saksena NK: Rapid and sensitive detection of severe acute respiratory syndrome coronavirus by rolling circle amplification. J Clin Microbiol 2005, 43:2339-2344.

25. Kong F, Tong Z, Chen X, Sorrell T, Wang B, Wu Q, Ellis D, Chen S: Rapid identification and differentiation of Trichophyton species, based on sequence polymorphisms of the ribosomal internal transcribed spacer regions, by rolling-circle amplification. J Clin Microbiol 2008, 46: I 192-I I99.

26. Zhou X, Kong F, Sorrell TC, Wang H, Duan Y, Chen SC: Practical method for detection and identification of Candida,
Aspergillus, and Scedosporium spp. by use of rolling-circle amplification. J Clin Microbiol 2008, 46:2423-2427.

27. Reference method for broth dilution antifungal susceptibility testing of yeasts. Approved standard NCCLS document M27-A3. 3rd edition. National Committee for Clinical Laboratory Standards: Wayne, PA; 2008.

28. Xiao L, Madison V, Chau AS, Loebenberg D, Palermo RE, McNicholas PM: Three-dimensional models of wild-type and mutated forms of cytochrome P450 14alpha-sterol demethylases from Aspergillus fumigatus and Candida albicans provide insights into posaconazole binding. Antimicrob Agents Chemother 2004, 48:568-574.

29. Asai K, Tsuchimori N, Okonogi K, Perfect JR, Gotoh O, Yoshida Y: Formation of azole-resistant Candida albicans by mutation of sterol 14-demethylase P450. Antimicrob Agents Chemother 1999, 43:1163-1169.

30. Yesilkaya H, Meacci F, Niemann S, Hillemann D, Rusch-Gerdes S, Barer MR, Andrew PW, Oggioni MR: Evaluation of molecularBeacon, TaqMan, and fluorescence resonance energy transfer probes for detection of antibiotic resistance-conferring single nucleotide polymorphisms in mixed Mycobacterium tuberculosis DNA extracts. J Clin Microbiol 2006, 44:3826-3829.

31. Gibson NJ: The use of real-time PCR methods in DNA sequence variation analysis. Clin Chim Acta; Int J Clin Chem 2006, 363:32-47.

32. Coste A, Turner V, Ischer F, Morschhauser J, Forche A, Selmecki A Berman J, Bille J, Sanglard D: A mutation in Taclp, a transcription factor regulating CDRI and CDR2, is coupled with loss of heterozygosity at chromosome 5 to mediate antifungal resistance in Candida albicans. Genetics 2006, 172:2139-2 I56.

33. MacPherson S, Akache B, Weber S, De Deken X, Raymond M, Turcotte B: Candida albicans zinc cluster protein Upc2p confers resistance to antifungal drugs and is an activator of ergosterol biosynthetic genes. Antimicrob Agents Chemother 2005, 49:1745-1752.

34. Mellado E, Garcia-Effron G, Alcazar-Fuoli L, Melchers WJ, Verweij PE, Cuenca-Estrella M, Rodriguez-Tudela JL: A new Aspergillus fumigatus resistance mechanism conferring in vitro cross-resistance to azole antifungals involves a combination of cyp5 IA alterations. Antimicrob Agents Chemother 2007, 5 I: I897-1904.

35. Garcia-Effron G, Dilger A, Alcazar-Fuoli L, Park S, Mellado E, Perlin DS: Rapid detection of triazole antifungal resistance in Aspergillus fumigatus. J Clin Microbiol 2008, 46: I 200-I 206.

36. Warren N, Hazen K: Candida, Cryptococcus, and other yeasts of medical importance. In Manual of Clinical Microbiology Edited by: Murray RPBE, Pfaller MA, Tenover FC, Yolken RH. Washington, D.C.: ASM Press; 1999:1 184-1199.

37. Reference method for broth dilution antifungal susceptibility testing of yeasts. Approved standard NCCLS document M27-A3. 3rd edition. National Committee for Clinical Laboratory Standards: Wayne, PA; 2002

38. Playford EG, Kong F, Sun Y, Wang H, Halliday C, Sorrell TC: Simultaneous detection and identification of Candida, Aspergillus, and Cryptococcus species by reverse line blot hybridization. J Clin Microbiol 2006, 44:876-880.

Publish with Bio Med Central and every scientist can read your work free of charge

"BioMed Central will be the most significant development for disseminating the results of biomedical research in our lifetime. "

Sir Paul Nurse, Cancer Research UK

Your research papers will be:

- available free of charge to the entire biomedical community

- peer reviewed and published immediately upon acceptance

- cited in PubMed and archived on PubMed Central

- yours - you keep the copyright 